\title{
Development of Robust SCAR Markers that Distinguish the Six Cultivated Brassica Species and Subspecies of the U-triangle
}

\author{
Federico L. Iñiguez-Luy and Michell E. Sass \\ University of Wisconsin-Madison, Department of Horticulture, 1575 Linden Drive, Madison, \\ WI 53706
}

Geunhwa Jung

University of Wisconsin-Madison, Department of Plant Pathology, 1630 Linden Drive, Madison, WI 53706

\author{
Mitrick A. Johns \\ Northern Illinois University, Department of Biological Sciences, DeKalb, IL 60115
}

James Nienhuis ${ }^{1}$

University of Wisconsin-Madison, Department of Horticulture, 1575 Linden Drive, Madison, WI 53706

AdDitional INDEX wORDs. Brassica, germplasm, molecular descriptors, RAPD, SCAR, U-triangle

\begin{abstract}
This research describes the development of robust molecular descriptors that are reliable and easy to use (PCR-based) for the proper classification of the six cultivated Brassica $\mathrm{L}$. species and subspecies that make up the $U$ triangle. Sequence characterized amplified regions (SCAR) were derived from DNA fragments generated by randomly amplified polymorphic DNA (RAPD) primers that distinguished the U-triangle Brassica species: $B$. rapa $\mathbf{L}$. (A, $\mathbf{n}=$ 10), B. nigra (L.) Koch (B, $n=8)$, B. oleracea L. $(\mathrm{C}, \mathbf{n}=9)$, B. juncea (L.) Czern (AB, $n=18)$, B. napus L. (AC, $n=19)$, and $B$. carinata Braun $(B C, n=17)$. The SCAR descriptors developed in this study reveal the presence-absence of a DNA fragment and sequence length polymorphisms to distinguish the three genomes $(\mathrm{A}, \mathrm{B}$, and $\mathrm{C})$ of the six cultivated Brassica species. These markers should prove to be useful in revealing misclassifications at the subspecies level. The amplification of a single DNA fragment and reduced sensitivity to reaction conditions make these SCAR descriptors ideal to accurately classify and organize large numbers of cultivated Brassica accessions typically present in large germplasm collections.
\end{abstract}

Plant germplasm organization and classification are important to the understanding, utilization, and conservation of plant genetic resources. Historically hybridization, cytogenetic studies, and morphological descriptors have contributed to the classification of accessions from the six cultivated Brassica species (GomezCampo, 1980, 1999; Prakash and Hinata, 1980; U, 1935). Understanding the relationships among the six cultivated Brassica genomes has played an important role in the development and improvement of new Brassica cultivars.

The degree of structural similarity among Brassica morphotypes provides important information about the relationships among the species (Warwick and Black, 1992). Morphological descriptors such as color, shape and size of vegetative and reproductive structures have been widely used in taxonomic studies of Brassica species (Gomez-Campo, 1980, 1999). However, species classification based exclusively on morphological features can

Received for publication 7 Dec. 2004. Accepted for publication 22 Feb. 2006 The authors would like to thank Drs. Richard Lower and James Coors for their critical review of this manuscript. We would also like to thank Drs. Paul Williams and Thomas Osborn of the Crucifer Genetics Cooperative for providing Brassica seed and for their vital input. The authors would also like to thank Daniel Gerhardt for his technical assistance. This research was funded by the National Science Foundation (grant \# ESI-9819051).

'To whom reprint requests should be addressed.E-mail address: nienhuis@wisc. edu be difficult because exceptions to general taxonomic rules exist (Dass and Nybom, 1967; Rodriguez et al., 1999). In addition, classification based on phenotypic data may be misinterpreted due to environmental effects on expression of morphological characteristics. Moreover, the use of morphological descriptors to distinguish among the six cultivated Brassica species can be difficult and time consuming for the non-specialist (Gomez-Campo, 1980) due to the immense variation within this set of species.

DNA-based molecular descriptors are useful in the characterization of genetic diversity and are less likely to be affected by environmental variation. Molecular descriptors have been used to distinguish among Capsicum L. (Rodriguez et al., 1999) and Picea A. Dietr. species (Perron et al., 1995), and among species of the Triticeae (Wei and Wang, 1995). In Brassica crops, RFLPs and RAPDs have been the predominant descriptors used for the study of the phylogeny of the genus (Lazaro and Aguinagalde, 1996; Song et al., 1988a, 1988b, 1990), genome evolution-organization (dos Santos et al., 1994; Quiros et al., 1991; Song et al., 1995), and cultivar identification (Diers and Osborn, 1994). More recently, AFLPs and SSRs have also been used for similar studies (Negi et al., 2000; Plieske and Stuss, 2001; Suwabe et al., 2002).

Genome and species-specific molecular descriptors have been observed among Brassica species (Heneen et al., 1995; Quiros et al., 1991). Quiros et al. (1991), reported 65 RAPD descriptors that were specific to the $\mathrm{A}, \mathrm{B}$, and $\mathrm{C}$ genome. RAPD markers 
have been useful in discriminating among the six Brassica taxa. However, lack of uniformity, consistency, and repeatability in amplifying similar fragments across laboratories has precluded broad adaptation of this technique (Quiros et al., 1995). In addition, little is known about the physical characteristics of the amplified fragments (Thormann et al., 1994), limiting their application in the study of the genetic structure of the Brassica species. The conversion of RAPD fragments to SCAR, by generating sequencespecific PCR primers pairs (Paran and Michelmore, 1993) provides more robust molecular descriptors that can be reliably used over a wide range of amplification conditions, and hence, are more repeatable across laboratories (Villand, 1998).

The specific research objectives of this study were to 1) clone and sequence RAPD descriptors identified in our laboratory as Brassica genome-specific markers 2) to develop SCAR primers ( $\approx 21$ mer) from the corresponding RAPD primers, and 3 ) to validate the usefulness of these SCAR primers across 104 random accessions representing the diploid and amphidiploid species of the U-triangle.

\section{Materials and Methods}

Plant material. A total of 104 Brassica accessions were randomly sampled from several germplasm banks and seed companies, including: two accessions (IMB 211 and R500) from T. Osborn (Dept. of Agronomy, Univ. of Wisconsin, Madison); six Brassica rapid-cycling populations from the Crucifer Genetics Cooperative [CrGC (Dept. of Plant Pathology, Univ. of Wisconsin, Madison); 11 accessions from the Asian Vegetable Research and Development Center (AVRDC), Tainan, Taiwan; 22 commercial cultivars (10 from W. Atlee Burpee and Co., Warminster, Pa.; 11 from Geo. W. Park Seed Co., Greenwood, S.C.; one from FerryMorse Seed Co., Fulton, Ky.); and 63 accessions from the U.S. Dept. of Agriculture, Agricultural Research Service, National Plant Germplasm System [NPGS (Ames, Iowa; Geneva, N.Y.; Fort Collins, Colo.)] (Table 1). The number of accessions sampled for each of the six cultivated Brassica species roughly corresponded to the number of accessions available in the NPGS collection; thus, for example more $B$. rapa (33 accessions) were sampled compared to B. nigra (eight accessions) (Table 1).

Six to 10 seeds of each subspecies were grown under fluorescent lights (150 umol) with an equal photoperiod. Two and one-half weeks after germination 0.8-1 g of immature leaf tissue (first true leaf) was harvested for DNA extraction. DNA isolation for RAPD screening and SCAR evaluation followed Johns et al. (1997).

IdentificAtion OF POLYMoRPhic RAPD FRAgMENTS. RAPD primers were selected based on two previous studies (Camargo et al., 1997; dos Santos et al., 1994) and a RAPD primer screen (data not published) carried out on 44 different Brassica accessions (Table 1). These three studies showed high levels of polymorphism among and within the six cultivated Brassica species. Twentyfive RAPD fragments were selected as potential candidates for SCAR conversion, based on their degree of species specificity. For example, to distinguish $B$. rapa from $B$. oleracea, RAPD fragments were selected that were present in $B$. rapa and absent in $B$. oleracea. The same criterion was applied for developing SCAR markers that could distinguish among subspecies categories. For example, in $B$. rapa RAPD fragments were selected that were present in pak choi [B. rapa ssp. chinensis (L) Hanelt] and absent in turnip (B. rapa ssp. rapifer Metzg). RAPD PCR mixtures were assembled as described by Skroch and Nienhuis (1995) and amplified using a PTC100 Programmable Thermal Controller (MJ Research, Waltham, Mass.) using cycling conditions described by Johns et al. (1997). Amplification products were resolved electrophoretically in $1.5 \%$ agarose gels.

CONVERSION OF RAPD FRAGMENTS INTO SPECIES-SPECIFIC SCAR MARKERS. RAPD fragments were converted into speciesspecific SCAR markers as described in Villand (1998). RAPD fragments of interest were excised from the agarose gel and placed in a microfuge tube with $20 \mu \mathrm{L} 0.1 \mathrm{X}$ TE buffer. Heating $\left(60{ }^{\circ} \mathrm{C}\right)$ and repipeting were used to dissolve the excised agarose gel containing the fragment of interest. PCR reactions were run similar to the initial RAPD reactions (Skroch and Nienhuis, 1995) using $5 \mu \mathrm{L}$ of the dissolved agarose fragments as the templates. The same cycling conditions were followed with the addition of a $72{ }^{\circ} \mathrm{C}$ extension for $30 \mathrm{~min}$ at the completion of the run. Reamplified products were separated in $1.5 \%$ agarose gels. All of the reamplified RAPD fragments were excised and purified following the BIO 101 Geneclean II gel purification protocol (Qbiogene, a division of MPBiomedicals, Irvine, Calif.). Concentrations of the purified DNA fragments were checked againstDNAconcentration standard electrophoresis. Ligation and transformation reactions were carried out using the Original TA Cloning kit (Invitrogen Corp., Carlsbad, Calif.). White colonies were selected for cell

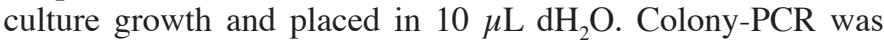
performed, using $5 \mu \mathrm{L}$ (template) of the colony-water mixture and universal primers [M13 forward (-20) and M13 reverse], to confirm the correct insertion size. Cultures of clones with the correct insertion size were grown from the remaining $5 \mu \mathrm{L}$ colony-water mixture. Plasmid purification followed the Qiagen (Valencia, Calif.) mini prep protocol. Cycle sequencing PCR reactions including BigDye Terminator mix from Perkin Elmer Applied Biosystems (Foster City, Calif.), universal forward and reverse primers, and 30-90 ng DNA were run in $20 \mu \mathrm{L}$ total volume reactions. The PCR cycle sequencing program profile was set as follows; $1 \mathrm{~min}$ at $96^{\circ} \mathrm{C}, 25$ cycles of $30 \mathrm{~s}$ at $96^{\circ} \mathrm{C}$, $15 \mathrm{~s}$ at $40{ }^{\circ} \mathrm{C}$, and $4 \mathrm{~min}$ at $60^{\circ} \mathrm{C}$ followed by a cool down at 4 ${ }^{\circ} \mathrm{C}$. Purification of the cycle sequencing products were carried out by adding $2.2 \mu \mathrm{L}$ of $3 \mathrm{M}$ sodium acetate $\mathrm{pH} 5.2$ and $50 \mu \mathrm{L}$ of $100 \%$ ethanol to each $20 \mu \mathrm{L}$ PCR reaction. Cloned amplification products were sequenced using an ABI 377XL automated DNA Sequencer at the University of Wisconsin Biotechnology Center DNA Sequence Facility (Madison). The resulting forward and reverse sequences were crosschecked for matching sequences beyond the original 10-mer RAPD primer sequence. Based on the obtained sequence information, approximately 10 more bases were added to the original ( $5^{\prime}$ to $3^{\prime}$ ) 10-mer RAPD sequence. The $\approx 20$-mer forward and reverse SCAR primers were synthesized at Operon Biotechnologies (Huntsville, Ala.).

SCAR ANALYSIS. The 25 SCAR primer pairs developed in this study were tested across 104 accessions representing the six cultivated Brassica species (Table 1). Amplification reactions and gel separation were described above for RAPD reactions, except that the annealing temperature $\left(50-60^{\circ} \mathrm{C}\right)$ was adjusted according to the specification of each set of SCAR primers (Table 2). The robustness of the developed SCAR markers was tested over a number of amplification conditions that included, 1) amplification in different thermal cyclers, 2) varied concentrations of template, 3 ) different concentrations of PCR components (magnesium chloride, PCR buffer and dNTPs), and 4) different PCR tubes and microtiter plates. 
Table 1. List of the 104 accessions from six cultivated Brassica species accessions for which SCAR markers were analyzed.

\begin{tabular}{|c|c|c|c|c|c|}
\hline Species and accession & $\begin{array}{l}\text { Intra-specific } \\
\text { name }\end{array}$ & $\begin{array}{l}\text { Common } \\
\text { name }\end{array}$ & $\begin{array}{l}\text { Species and } \\
\text { accession }\end{array}$ & $\begin{array}{l}\text { Intra-specific } \\
\text { name }\end{array}$ & $\begin{array}{l}\text { Common } \\
\text { name }\end{array}$ \\
\hline \multicolumn{6}{|l|}{ Brassica rapa L. $(n=10)$} \\
\hline $\operatorname{CrGC} 1-1^{x}$ & & rapid cycling & PI462224 & var. botytis & cauliflower \\
\hline IMB $211^{2}$ & & rapid cycling & Earliana $^{2}$ & var. capitata L. & cabbage \\
\hline Bp 09 & ssp. chinensis (L) Hanelt & pak choi & Salad Delight ${ }^{2}$ & var. capitata & cabbage \\
\hline Bp 31 & ssp. chinensis & pak choi & Everlast Hybrid $^{2}$ & var. capitata & cabbage \\
\hline Joi Choi Hybrid ${ }^{2}$ & ssp. chinensis & pak choi & PI261769 & var, capitata & cabbage \\
\hline Joi Choi Hybrid ${ }^{x}$ & ssp. chinensis & pak choi & P1296133 & var. capitata & cabbage \\
\hline $\mathrm{P} 1430484^{2}$ & ssp. chinensis & pak choi & Jade Cross Early Hybrid ${ }^{2}$ & var. gemmifera Zenker & brussels sprouts \\
\hline $\mathrm{P} 1430485$ & ssp. chinensis & pak choi & Prince Marvel ${ }^{2}$ & var. gemmitera & brussels sprouts \\
\hline PI478324 & ssp. chinensis & pak choi & $\mathrm{PI} 261759$ & var. gemmitera & brussels sprouts \\
\hline $\mathrm{BC} 11^{2}$ & var. parachinensis (Bailey) Hanelt & choi sum & NSL34225 & var. gemmitera & brussels sprouts \\
\hline $\mathrm{BC} 14^{x}$ & var. parachinensis & choi sum & Express Forcer ${ }^{2}$ & var. gongylodes L. & kohlirabi \\
\hline $\mathrm{BCC} 12$ & ssp. pekinensis (Lour.) Hanelt & chinese cabbage & PI188611 & var. gongylodes & kohlrabi \\
\hline $\mathrm{BCC} 23$ & ssp. pekinensis & chinese cabbage & NSL6269 & var. gongyiodes & kohirabi \\
\hline Orient Express ${ }^{2}$ & ssp. pekinensis & chinese cabbage & NSL6270 & var. gongyiodes & kohirabi \\
\hline Flash Hybrid ${ }^{z}$ & ssp. pekinensis & chinese cabbage & Green Goliath & var. talica Plenck. & brocooli \\
\hline PI257237 & ssp. pekinensis & chinese cabbage & Gallant Hybrid ${ }^{2}$ & var. italica & broccoli \\
\hline PI419127 & ssp. pekinensis & chinese cabbage & PI507856 & var. sabauda L. & savoy cabbage \\
\hline $\mathrm{Pl} 48975^{2}$ & ssp. pekinensis & chinese cabbage & Champion Hybrid ${ }^{2}$ & var. sabelica & collard \\
\hline Ames23075 & ssp. pekinensis & chinese cabbage & NSL6143 & var. sabellica & collard \\
\hline NSL6007 & ssp. pekinensis & chinese cabbage & NSL6152 & var. sabellica & collard \\
\hline PI340202 & ssp. dichotoma (Roxb.) Hanet & indian rape & NSL6697 & var. sabellica & collard \\
\hline Ames $23083^{2}$ & ssp. aleifera (DC.) Metzg & turnip rape & NSL6797 & var. sabellica & collard \\
\hline NSL165769 ${ }^{2}$ & ssp. abeĩera & turnip rape & $\begin{array}{l}\text { Brassica juncea (L.) Czern. } \\
(\mathrm{n}=18)\end{array}$ & & \\
\hline Ames 25111 & ssp. oleưera & turnip rape & $\mathrm{CrGC} 4-1$ & var. oleifera Prain & rapid cycling \\
\hline PTWG $5469^{2}$ & ssp. rapifera Metzg & turnip & $\mathrm{BjO3}$ & var. oleưera & indian mustard \\
\hline Ames $1920 B$ & ssp. rapitera & turnip & $B j 10$ & var. oleifera & indian mustard \\
\hline $\mathrm{R}^{500^{x}}$ & ssp. trilocularis (Roxb.) Hanelt & yellow sarson & Florida Broad Leaf ${ }^{2}$ & var. oleifera & indian mustard \\
\hline P1346882 & ssp. trilocularis & yellow sarson & Florida Broad Leaf ${ }^{2}$ & var, oleivera & indian mustard \\
\hline $\mathrm{PI} 347608^{2}$ & ssp. trilocularis & yellow sarson & $\mathrm{PI} 120923$ & var. oleitera & indian musta \\
\hline P1426421 & ssp. trilocularis & yellow sarson & PI179859 & var, oleilera & indian musta \\
\hline PI459020 & ssp. trilocularis & yellow sarson & PI288725 & var, oleilera & indian musta \\
\hline Spring $^{2}$ & var. Utivis & broccoli raab & PI426333 & var, oleifera & indian musta \\
\hline 31BR & var. Utwis & broccoli raab & Ames $23094^{x}$ & var. oleifera & indian musta \\
\hline \multicolumn{3}{|c|}{ Brassica nigra (L.) Koch (n=8) } & Ames 725 & & oriental mus \\
\hline CrGC2-1 & & rapid cycling & PI531272 & var. longidens L. H. Bailey & \\
\hline
\end{tabular}


Table 1. Continued.

\begin{tabular}{|c|c|c|c|c|c|}
\hline Species and accession & $\begin{array}{c}\text { Intra-specific } \\
\text { name }\end{array}$ & $\begin{array}{c}\text { Common } \\
\text { name }\end{array}$ & $\begin{array}{l}\text { Species and } \\
\text { accession }\end{array}$ & $\begin{array}{c}\text { Intra-specific } \\
\text { name }\end{array}$ & $\begin{array}{c}\text { Common } \\
\text { name }\end{array}$ \\
\hline PI254362 & & black mustard & Brassica napus L. (n=19) & & \\
\hline PI271444 $4^{x}$ & & black mustard & CrGC5-1 $1^{2}$ & var. oleifera Delile & rapid cycling \\
\hline PI273638 ${ }^{x}$ & & black mustard & $\mathrm{P} 1250135^{x}$ & var. oleifera & colza \\
\hline PI368378 & & black mustard & PI311728 & var. oleivera & colza \\
\hline P1592737 & & black mustard & P1535865 & var. Oleifera & colza \\
\hline PI603018 & & black mustard & Ames $22970^{2}$ & var. oleifera & colea \\
\hline Ames 24227 & & black mustard & P1279688 & var. rapoüera (DC) Metzger & rutabaga \\
\hline Brassica oleracea $\mathrm{L},(\mathrm{n}=9)$ & & & $\mathrm{P} 1458941$ & var. rapüfora & rutabaga \\
\hline $\mathrm{CrGC} 3-9^{2}$ & & rapid cycling & $\mathrm{P} 1469737^{z}$ & var. rapifera & rutabaga \\
\hline Dwarf Blue ${ }^{2}$ & ssp. acephala (DC.) Schubler & kale & $\mathrm{P} 1469856^{2}$ & var. rapifera & rutabaga \\
\hline Winterbor Hybrid ${ }^{2}$ & var. Alboglabra (Bailey) Musil & kale & Pl469881 & var. rapifera & rutabaga \\
\hline $\mathrm{Ba} 08^{x}$ & var. Alboglabva & chinese kale & $\begin{array}{l}\text { Brassica carinata Braun. } \\
(\mathrm{n}=17)\end{array}$ & & \\
\hline Ba24 & var. Alboglabra & chinese kale & $\mathrm{CrGC} 6-1^{2}$ & & rapid cycling \\
\hline PI249556 & var. botrytis $\mathrm{L}$. & cauliflower & PI193459 & & ethiopian mu \\
\hline Green Goddess Hybrid ${ }^{2}$ & var. botrytis & cauliflower & PI193959 & & ethiopian me \\
\hline Ravella Hybrid ${ }^{2}$ & var. botrytis & cauliflower & Pl195921 $1^{z}$ & & ethiopian mu \\
\hline Shannon ${ }^{2}$ & var. botrytis & cauliflower & PI331378 & & ethiopian mu \\
\hline P1208480 & var. botrytis & cauliflower & P1390133 & & ethiopian mi \\
\hline $\mathrm{P} 1241609^{2}$ & var. botrytis & cauliflower & Ames 19183 & & ethiopian m. \\
\hline PI264651 & var. botrytis & cauliflower & & & \\
\hline
\end{tabular}

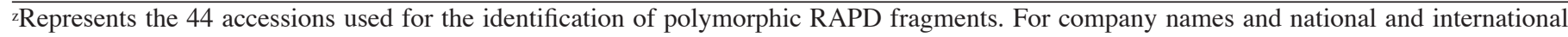
germplasm repository centers please see the materials and method section.

\section{Results}

SCAR CONVERSION. Twenty-five RAPD fragments were converted to SCAR makers by developing sequence-specific primer pairs. Each of these primer pairs amplified prominent fragments that varied in size from 240 to $1100 \mathrm{bp}$ (Table 2). Eighteen of the 25 (72\% conversion rate) SCAR primer pairs produced a portion of the same fragment pattern that was observed for the corresponding RAPD reaction. For the remaining seven SCAR primer pairs, polymorphisms detected in the initial RAPD reaction were lost (e.g., they revealed monomorphic PCR products). These SCAR markers were discarded for further consideration.

SCAR ANALYSIS. In general, SCAR primer amplification patterns were identical for all accessions within each subspecies; therefore, the patterns of only representative accessions from Table 1 are presented (Table 3 ). The SCAR analysis revealed that 2 out of the 64 accessions tested deviated from their respective subspecies specific pattern (and in one case led to the detection of a misclassification). The SCAR reaction and analysis was repeated three times under different laboratory conditions (thermal cycler manufacturer, different PCR component concentrations, etc.) to test for procedure repeatability. Similar results in the PCR profile were obtained under the different laboratory conditions as previously described.
SPECIES-SPECIFIC SCAR MARKERS. Seven SCAR primer pairs (primers 1 to 7), out of the eighteen SCAR primer pairs developed in this study, differentiated the six cultivated Brassica species that form the U-triangle (Tables 1 and 3). SCAR primers 1 to 7 revealed two types of polymorphic patterns, 1) the presence or absence of PCR amplification fragments associated with one of the Brassica genomes (A, B, or $\mathrm{C})$, or 2) sequence length polymorphism associated with specific Brassica genome (A, B, or C) fragment size (Fig. 1). The two types of polymorphisms were consistent in both diploid and amphidiploid species. Thus, for example, the SCAR amplification products that were observed in all accessions of the diploid species, $B$. rapa (A), were also observed in the amphidiploid species $B$. juncea $(\mathrm{AB})$ and $B$. napus $(\mathrm{AC})$ that also contain the $\mathrm{A}$ genome. In a similar manner, SCAR amplification products observed in the diploid B genome of B. nigra and the diploid $\mathrm{C}$ genome of $B$. oleracea, were also observed in accessions from their related amphidiploid species, B. juncea (AB), B.napus (AC), and $B$. carinata (BC), respectively (Table 3 ).

SCAR primers 1, 2, and 3 amplified a single DNA fragment at 860,610 , and $710 \mathrm{bp}$ in length, respectively, in all accessions containing the Agenome (Tables 2 and 3 ). SCAR primer 4 amplified a single DNA fragment of $655 \mathrm{bp}$ in length in all accessions containing the A genome and two DNA fragments of 320/661 bp in length, in all accessions containing the B genome (Tables 
Table 2. Brassica species-specific SCAR marker type, primer sequences, annealing temperatures, and expected amplicon size.

\begin{tabular}{|c|c|c|c|c|}
\hline \multirow{7}{*}{$\begin{array}{l}\text { Species-specific } \\
\text { SCAR primers }\end{array}$} & 1 & $\begin{array}{l}\text { F: 5'-ACGGGACCTGATGATACAAT-3' } \\
\text { R: 5'-ACGGGACCTGTTTGAGGGAA-3' }\end{array}$ & 60.0 & A:860 \\
\hline & 2 & $\begin{array}{l}\text { F: 5'-GTCGCCGTCAAGAAATCCGC-3' } \\
\text { R: 5'-GTCGCCGTCACGTAGCATGC-3' }\end{array}$ & 65.5 & $A: 610$ \\
\hline & 3 & $\begin{array}{l}\text { F: 5'-CGTAACCTTGCTTATTCTTGC-3' } \\
\text { R: 5'-CGTAACCTTGTTCTATTATC-3 }\end{array}$ & 54.6 & $A: 710$ \\
\hline & 4 & $\begin{array}{l}\text { F: 5'-CCTGCTTACGATATGGCTTGG-3' } \\
\text { R: 5'-CCTGCTTACGGTACCAAC-3' }\end{array}$ & 61.2 & $\begin{array}{l}A: 655 \\
B: 320 / 661^{y}\end{array}$ \\
\hline & 5 & $\begin{array}{l}\text { F: 5'-CTCACCGTCCAGCCCGTGCG-3' } \\
\text { R: 5'-CTCACCGTCCTCTAACAAA-3' }\end{array}$ & 62.0 & $\begin{array}{l}\text { A:880 } \\
\text { B:550/710 } \\
C: 910\end{array}$ \\
\hline & 6 & $\begin{array}{l}\text { F: 5'-GACCGCTTGTGGAAGAGAG-3' } \\
\text { R: 5'-GACCGCTTGTCTGAGGATGG-3' }\end{array}$ & 63.4 & $\begin{array}{l}\text { A:680 } \\
B: 680 / 720 \\
\text { C:700 }\end{array}$ \\
\hline & 7 & $\begin{array}{l}\text { F: 5'-CGAGCTTTGAAGCAAGGAGG-3' } \\
\text { R: 5'-CGAGCTTTGAGTTGTACTGC-3' }\end{array}$ & 61.4 & $\begin{array}{l}A: 680 \\
B: 710 \\
C: 1100\end{array}$ \\
\hline \multirow{11}{*}{$\begin{array}{l}\text { Subspecies- } \\
\text { specific SCAR }\end{array}$} & 8 & $\begin{array}{l}\text { R: 5'-GGGGTGAACGACAACTAATTAAA-3', } \\
\text { R:-GGGGTGACGATCGATTTTGAA-3' }\end{array}$ & 60.0 & B: 600 \\
\hline & 9 & $\begin{array}{l}\text { F: 5'-GACCGCTTGTCCGCAACAGT-3' } \\
\text { R: 5'-GACCGCTTGTATCTATGTTTAGTC-3' }\end{array}$ & 62.8 & $\begin{array}{l}\text { A:1100 } \\
C: 600\end{array}$ \\
\hline & 10 & $\begin{array}{l}\text { F: 5'-ACGGTACCAGGTTGAGATA-3' } \\
\text { R: 5'-ACGGTACCAGAAGCAAACTA-3' }\end{array}$ & 65.0 & A:850 \\
\hline & 11 & $\begin{array}{l}\text { F: 5'-GACCGCTTGTCGATTTAAAAGG-3' } \\
\text { R: 5'-GACCGCTTGTAGTCACATATG-3' }\end{array}$ & 60.7 & $\begin{array}{l}\text { A:670 } \\
\text { C:720 }\end{array}$ \\
\hline & 12 & $\begin{array}{l}\text { F: 5'-GACCGCTTGTCGATTTAAGGA-3' } \\
\text { R: 5'-GACCGCTTGTAGTCACATAT-3' }\end{array}$ & 59.2 & $\begin{array}{l}A: 680 \\
C: 750\end{array}$ \\
\hline & 13 & $\begin{array}{l}\text { F: 5'-TCTGGCGCACTTGACTGTCG-3' } \\
\text { R: 5'-TCTGGCGCACCAACTAACTCAGACG-3' }\end{array}$ & 66.1 & $\begin{array}{l}A: 620 \\
C: 600\end{array}$ \\
\hline & 14 & $\begin{array}{l}\text { F: 5'-GACCGCTTGTCGATTTTAAC-3' } \\
\text { R: 5'-GACCGCTTGTAGTCACATAT-3' }\end{array}$ & 58.3 & $A: 680 A+: 710^{x}$ \\
\hline & 15 & $\begin{array}{l}\text { F: 5'-CCCCTCGAATCAATCAATC-3' } \\
\text { R: 5'-CCCCTCGAATATTCCATTAC-3' }\end{array}$ & 58.1 & $\begin{array}{l}A: 710 A+: 800^{X} \\
C: 750\end{array}$ \\
\hline & 16 & $\begin{array}{l}\text { F: 5'-GGGCGACTACAACAACCAG-3' } \\
\text { R: 5'-GGGCGACTACTTCAGGGCGG-3' }\end{array}$ & 62.0 & $\begin{array}{l}\text { C:440 } \\
\text { B:240 }\end{array}$ \\
\hline & 17 & $\begin{array}{l}\text { F: 5'-GTGAGGCGTCGATAGGCGGC-3' } \\
\text { R: 5'-GTGAGGCGTCTCTTGATGACATT-3' }\end{array}$ & 65.5 & A:600 \\
\hline & 18 & $\begin{array}{l}\text { F: 5'-GGACCCAACCCTCCTTTAGAA-3' } \\
\text { R:5'-GGACCCAACCTTAGACTACG-3' }\end{array}$ & 62.0 & A:840 \\
\hline
\end{tabular}

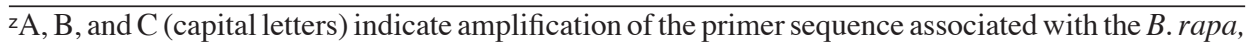
$B$. oleracea, and $B$. nigra genomes, respectively, in both diploid and amphidiploid species.

y Two molecular sizes separated by a slash bar indicate the present of two DNA fragments for that particular SCAR marker.

${ }^{\mathrm{x}} \mathrm{A}+$ indicates sequence length polymorphism for the fragment amplified in the A genome. 
2 and 3). Primer 5 amplified a single DNA fragment (880 bp) in all accessions containing the A genome; two DNA fragments (550/710 bp) in all accessions containing the B genome; and a single fragment $(910 \mathrm{bp})$ in all accessions containing the $\mathrm{C}$ genome. Primer 6 amplified a single DNA fragment of $680 \mathrm{bp}$ in all accessions containing the A genome; two DNA fragments of 680/720 bp, in all accessions containing the B genome; and a single fragment of $700 \mathrm{bp}$ in all accessions containing the $\mathrm{C}$ genome. Primer 7 amplified a single DNA fragment of $680 \mathrm{bp}$ in all accessions containing the A genome; a single DNA fragment of $710 \mathrm{bp}$ in all accessions containing the B genome; and a single DNA fragment of $1100 \mathrm{bp}$ in all accessions containing the C genome (Tables 2 and 3). SCAR primers 6 and 7 did not reveal an amplification product for the $\mathrm{B}$ genome in the amphidiploid species $B$. juncea (Tables 2 and 3 ).

SubSPECIES-SPECIFIC SCAR MARKERS. Nine SCAR primer pairs (primers 8 to 18), all revealed either presence-absence or sequence length polymorphism at the subspecies level. Song et al. (1988a, 1988b) divided B. rapa subspecies into a European group including, turnip, turnip rape and yellow sarson; and an east Asian group, including pak choi, choi sum, chinese cabbage, and broccoli raab. SCAR primers 8, 9, and 10 each amplified a single fragment of 670,1100 , and $850 \mathrm{bp}$, respectively, in all accessions of the east Asian group. In contrast, SCAR primers 11, 12 , and 13 each amplified a single fragment of 670, 680, and 620 $\mathrm{bp}$, respectively, in all accessions of the European group. SCAR primer pairs 14 and 15 revealed sequence length polymorphism among the European B. rapa subspecies. Primer 14 amplified two DNA fragments of 680 and $710 \mathrm{bp}$ that distinguished turnip rapes from turnips, respectively. Primer 15 amplified two DNA fragments of 710 and $800 \mathrm{bp}$ that distinguished yellow sarsons from turnips and turnip rapes, respectively (Tables 2 and 3 ).

Among B. oleracea subspecies, SCAR primer pairs 12 and 16 revealed presence-absence polymorphisms between, cauliflower and cabbage compared to chinese kale, cauliflower, kohlrabi, and broccoli. Primer 12 amplified a single DNA fragment of $750 \mathrm{bp}$ in all B. oleracea accessions except for cauliflower and cabbage. Primer 16 amplified a single DNA fragment of $440 \mathrm{bp}$ in all $B$. oleracea accessions except for chinese kale, cauliflower, kohlrabi, and broccoli (Tables 2 and 3).

Among B. juncea (AB) subspecies, SCAR primer pairs 9, 12, 17 and 18 revealed presence-absence polymorphisms between indian mustard and B. juncea var. longidens L.H. Bailey. Primer $9,12,17$, and 18 each amplified a single DNA fragment of 1100 , 680,600 , and $840 \mathrm{bp}$, respectively; corresponding to the Agenome, in all indian mustard accessions (Table 2 and 3 ).

Among B. napus (AC) subspecies, SCAR primer pairs 8, 9 , and 13 revealed presence-absence polymorphisms between colza and rutabaga. Primer 8 amplified a single DNA fragment of $670 \mathrm{bp}$ corresponding to the A genome in all rutabaga accessions. Primer 9 amplified a single DNA fragments for each of the $\mathrm{A}$ and $\mathrm{C}$ genomes of 1100 and $600 \mathrm{bp}$, respectively, except for colza accessions where the A genome fragment was not amplified. Primer 13 amplified a single DNA fragment for each of the $\mathrm{A}$ and $\mathrm{C}$ genomes of 620 and $600 \mathrm{bp}$, respectively, with the exception of the rutabaga accessions where the $\mathrm{C}$ genome was not amplified (Tables 2 and 3).

Potential misclassifications. Results presented in Table 3 indicate that misclassification may have occurred in two of 64 randomly chosen accessions from the NPGS. Accession, NSL6007 is labeled as B. rapa ssp. pekinensis (Lour.) Hanelt (chinese cabbage); however, the banding patterns of this acces- sion using primers $8,9,10,11,12,13,14$, and 15 are not like other $B$. rapa ssp. pekinensis accessions, but are identical to $B$. rapa ssp. oleifera (DC.) Metzg accessions (Table 3). Accession NSL6007 was grown in the greenhouse and was confirmed to be a turnip (B. rapa ssp. oleifera) (data not shown). In addition, SCAR banding pattern using primer 5 revealed an inconsistency in the amplification pattern of accession PI340202. This accession is labeled as indian rape B. rapa ssp. dichotoma (Roxb.) Hanelt. However, SCAR primer 5 profiles revealed an amplification pattern similar to the amphidiploid B. napus species (Fig. 1, Table 3). DNA extraction and PCR amplification were repeated and the same PCR profile was obtained.

\section{Discussion}

Previous studies (Negi et al., 2000; Quiros et al., 1991; Song et al. 1988a) reported the use of various molecular markers (AFLP, RFLP, and RAPD) for the understanding of relationships among the six cultivated Brassica species. However, marker-types such as RFLPor AFLP are time-consuming and require the use of isotopes and/or specialized laboratory equipment. RAPD markers are easier to use; however, they may be unrepeatable across laboratories (Gomez-Campo, 1999). In this study, a set of 18 SCAR primers were developed as diagnostic descriptors for the discrimination among the six cultivated Brassica species and subspecies. SCAR markers are low-cost PCR-based molecular descriptors that are repeatable in their amplification pattern across laboratories (Negi et al., 2000; Paran and Michelmore, 1993). The 18 SCAR primer pairs developed in this study were robust under various laboratory conditions, suggesting that these SCAR primers produce repeatable polymorphic patterns. The speed and simplicity of DNA extraction coupled with the low cost and consistent amplification patterns of SCAR markers make them ideal molecular descriptors for sampling large numbers of accessions.

The cost to characterize large numbers of accessions at national and international germplasm banks often precludes the systematic characterization of all accessions (Villand, 1998). In the case of the six cultivated Brassica species (and subspecies) one technique that can be used to differentiate them, apart from molecular markers, has been the use of cytogenetics (U, 1935). This allows for the proper identification of chromosomes number and thus the differentiation of the species. However, these methodologies can become complex due to the small size and similar length of Brassica chromosomes (Hasterok and Maluszynska, 2000; Howell et al., 2002; Snowdon et al., 2002). In addition, the employment of cytometric techniques requires specialized equipment that increases the cost of species classification. In this framework, the availability of fast, low cost and reliable molecular markers allows for proper classification and conservation of plant genetic resources.

The two SCAR marker types developed in this study (presence/absence and sequence length polymorphism) can reliably discriminate among the six cultivated Brassica species. Nevertheless, characterization based solely on the presence/absence of a fragment may be subject to experimental errors. The failure to amplify a fragment could be attributed to errors in the preparation of the PCR reaction mixture. The most useful SCAR markers are those that revealed sequence length polymorphism among species because amplification products are always expected. Sequence length polymorphism does not necessarily imply that homologous DNA fragments are being amplified by a given SCAR primer pair in polymorphic accessions. This is due to the little physical 
Table 3. Pattern of SCAR primers amplification among representative samples of six cultivated Brassica species. $^{\mathrm{Z}}$

Polymorphism type and SCAR markers 1-18 amplification pattern

\begin{tabular}{|c|c|c|c|c|c|c|c|c|c|c|c|c|c|c|c|c|c|c|c|c|}
\hline \multirow{2}{*}{$\begin{array}{l}\text { Species and } \\
\text { Accession ID }\end{array}$} & \multirow[b]{2}{*}{ Intra-specific Name } & \multirow[b]{2}{*}{ Common name } & \multicolumn{7}{|c|}{ Species-specific SCAR primers } & \multicolumn{11}{|c|}{ Subspecies-specific SCAR primers } \\
\hline & & & 1 & 2 & 3 & 4 & 5 & 6 & 7 & 8 & 9 & 10 & 11 & 12 & 13 & 14 & 15 & 16 & 17 & 18 \\
\hline $\begin{array}{l}\text { B. rapa L. } \\
(\mathrm{n}=10)\end{array}$ & Diploid & Diploid & & & & & & & & & & & & & & & & & & \\
\hline PI430484 & subsp. chinensis $(7)^{y}$ & pak choi & $A^{x}$ & A & A & A & A & A & A & A & A & A & 0 & 0 & 0 & 0 & A & 0 & A & A \\
\hline BC11 & var. parachinensis (2) & choi sum & A & A & A & A & A & A & A & A & A & A & 0 & 0 & 0 & 0 & A & 0 & A & A \\
\hline PI257237 & subsp. pekinensis (8) & chinese cabbage & A & A & A & A & A & A & A & A & A & A & 0 & 0 & 0 & 0 & A & 0 & A & A \\
\hline NSL6007 & Misclassified $^{u}$ & chinese cabbage & A & A & A & A & A & A & A & 0 & 0 & 0 & A & A & A & $A+{ }^{w}$ & $A+$ & 0 & A & A \\
\hline PI340202 & Misclassified $^{u}$ & indian rape & A & A & A & A & AC & A & A & 0 & A & A & A & A & A & A & A & 0 & A & A \\
\hline NSL165769 & subsp. oleifera (3) & turnip rape & A & A & A & A & A & A & A & 0 & 0 & 0 & A & A & A & A & $A+$ & 0 & A & A \\
\hline Ames19208 & subsp. rapifera (2) & turnip & A & A & A & A & A & A & A & 0 & 0 & 0 & A & A & A & $\mathrm{A}^{+}$ & $A^{+}$ & 0 & A & A \\
\hline PI346882 & subsp. trilocularis (5) & yellow sarson & A & A & A & A & A & A & A & 0 & 0 & 0 & A & A & A & A & A & 0 & A & A \\
\hline $31 \mathrm{BR}$ & var. utilis (2) & broccoli raab & A & A & A & A & A & A & A & A & A & A & 0 & 0 & 0 & 0 & A & 0 & A & A \\
\hline $\begin{array}{l}\text { B. nigra (L.) Koch } \\
(\mathrm{n}=8)\end{array}$ & Diploid & Diploid & & & & & & & & & & & & & & & & & & \\
\hline PI254362 & (8) & black mustard & $0^{v}$ & 0 & 0 & $B^{x}$ & B & B & B & B & 0 & 0 & 0 & B & 0 & 0 & 0 & B & 0 & 0 \\
\hline$(\mathrm{n}=9)$ & Diploid & Diploid & & & & & & & & & & & & & & & & & & \\
\hline Dwarf Blue & subsp. acephala (2) & kale & 0 & 0 & 0 & 0 & $C^{x}$ & c & $\mathrm{C}$ & 0 & c & 0 & $\mathrm{C}$ & c & C & 0 & C & $c$ & 0 & 0 \\
\hline Ba08 & var. alboglabra (3) & chinese kale & 0 & 0 & 0 & 0 & $\mathrm{c}$ & $c$ & C & 0 & c & 0 & C & c & c & 0 & c & 0 & 0 & 0 \\
\hline PI208480 & var. botrytis (7) & cauliflower & 0 & 0 & 0 & 0 & C & C & C & 0 & C & 0 & C & 0 & C & 0 & C & 0 & 0 & 0 \\
\hline PI261769 & var. capitata (5) & cabbage & 0 & 0 & 0 & 0 & C & C & C & 0 & C & 0 & C & 0 & C & 0 & C & C & 0 & 0 \\
\hline PI261759 & var. gemmifera (4) & brussels sprouts & 0 & 0 & 0 & 0 & C & C & C & 0 & c & 0 & C & C & C & 0 & c & C & 0 & 0 \\
\hline PI188611 & var. gongylodes (4) & kohlrabi & 0 & 0 & 0 & 0 & C & C & C & 0 & C & 0 & C & C & C & 0 & c & 0 & 0 & 0 \\
\hline Green Goliath & var. italica (2) & broccoli & 0 & 0 & 0 & 0 & $\mathrm{C}$ & $c$ & C & 0 & c & 0 & C & c & c & 0 & c & 0 & 0 & 0 \\
\hline PI507856 & var. sabauda (1) & savoy cabbage & 0 & 0 & 0 & 0 & C & C & C & 0 & C & 0 & C & C & C & 0 & C & C & 0 & 0 \\
\hline NSL6143 & var. sabellica (5) & collard & 0 & 0 & 0 & 0 & C & C & C & 0 & C & 0 & C & c & C & 0 & C & C & 0 & 0 \\
\hline $\begin{array}{l}\text { B. juncea (L.) } \\
\text { Czern. }(n=18)\end{array}$ & Amphidiploid & Amphidiploid & & & & & & & & & & & & & & & & & & \\
\hline PI120923 & var. oleifera (10) & indian mustard & $A b^{x}$ & $A b$ & $A b$ & $A B$ & $A B$ & $A b$ & $a B^{x}$ & $A B$ & $\mathrm{Ab}$ & $A b$ & 0 & $\mathrm{Ab}$ & $\mathrm{Ab}$ & 0 & $A b$ & $\mathrm{aB}$ & $A b$ & $\mathrm{Ab}$ \\
\hline PI531272 & var. longidens (1) & & $A b$ & $\mathrm{Ab}$ & $A b$ & $A B$ & $A B$ & $A b$ & $A b$ & $A B$ & 0 & $A b$ & 0 & 0 & $\mathrm{Ab}$ & 0 & $A b$ & $\mathrm{aB}$ & 0 & 0 \\
\hline $\begin{array}{l}\text { B. napus } \mathrm{L} \text {. } \\
(\mathrm{n}=19)\end{array}$ & Amphidiploid & Amphidiploid & & & & & & & & & & & & & & & & & & \\
\hline PI535865 & var. oleifera (5) & colza & $A c^{x}$ & Ac & Ac & $\mathrm{Ac}$ & AC & AC & AC & 0 & $\mathrm{ac}^{\mathrm{x}}$ & $\mathrm{Ac}$ & AC & $\mathrm{Ac}$ & $\mathrm{AC}$ & Ac & AC & 0 & 0 & $\mathrm{Ac}$ \\
\hline PI279688 & var. rapifera (5) & rutabaga & Ac & Ac & Ac & Ac & $A C$ & AC & $A C$ & Ac & AC & Ac & AC & Ac & $\mathrm{aC}$ & $A c$ & AC & 0 & 0 & Ac \\
\hline $\begin{array}{l}\text { B. carinata Braun. } \\
(n=17)\end{array}$ & Amphidiploid & Amphidiploid & & & & & & & & & & & & & & & & & & \\
\hline Pl193459 & (7) & ethiopian mustard & 0 & 0 & 0 & $\mathrm{Bc}^{\mathrm{x}}$ & $\mathrm{BC}$ & $\mathrm{BC}$ & $B C$ & $\mathrm{Bc}$ & $\mathrm{bc}$ & 0 & $\mathrm{bC}$ & $\mathrm{bc}$ & $\mathrm{bc}$ & 0 & $\mathrm{bc}$ & $\mathrm{Bc}$ & 0 & 0 \\
\hline
\end{tabular}

${ }_{\mathrm{z}}^{\mathrm{S} C A R}$ primer amplification patterns were identical for all accessions with each subspecies; therefore, the pattern of only a representative accession is presented.

yNumbers in parenthesis indicate the total number of accessions for which the SCAR primer amplification patterns were identical (see Table 1 for complete list of accessions).

${ }^{\mathrm{x}} \mathrm{A}, \mathrm{B}$, and C (capital letters) indicate amplification of the primer sequence associated with the $B$. rapa, B. oleracea, and B. nigra genomes in both diploid and amphidiploid species, respectively. Lowercase letters (a, b, and c) associated with amphidiploid species indicates which genome was not amplified by a specific primer.

wA+ indicates length polymorphism for the fragment amplified in the A genome.

${ }^{v} 0$ indicates that the SCAR primer did not amplify the genome associated with that specific diploid or amphidiploid species. uMisclassified indicates that SCAR marker amplification patterns are inconsistent with the species or subspecies designation previously assigned to a particular accession. 
Genomes

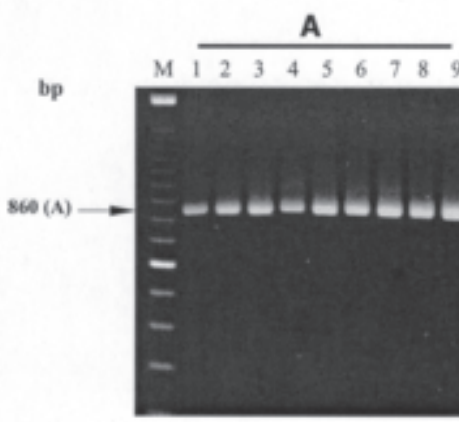

B

C

AB $\quad$ AC $\quad$ BC 9 $10111213141516171819202122232425262728 \mathrm{Ca} \mathrm{M}$

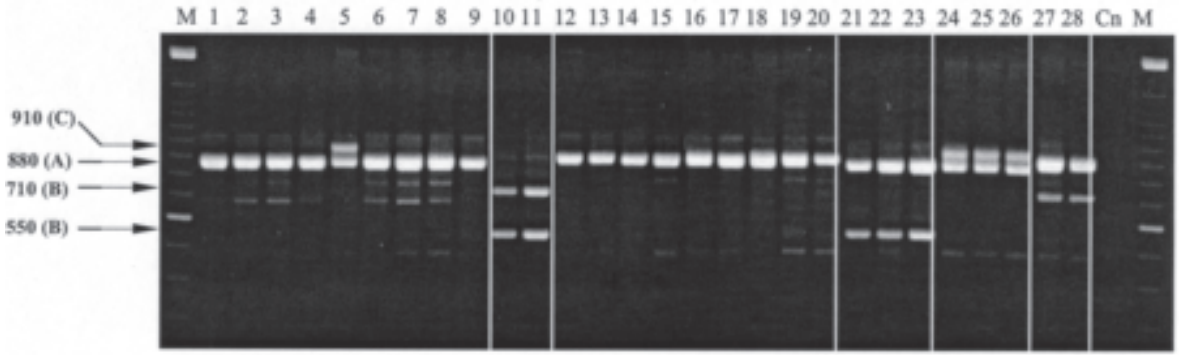

Fig. 1. SCAR marker profile for primer 1 corresponding to the presence-absence polymorphism (top gel) and primer 5 corresponding to sequence length polymorphism (bottom gel). Lanes 1-9 represent the A genome of Brassica rapa in the following order: rapid-cycling B. rapa, pak choi, choi sum, chinese cabbage, indian rape, turnip rape, turnip, yellow sarson, and broccoli raab. Lanes 10-11 represent the B genome of $B$. nigra in the following order: rapid-cycling $B$. nigra and black mustard. Lanes 12-20 represent the C genome of $B$. oleracea in the following order: rapid-cycling $B$. oleracea, kale, chinese kale, cauliflower, cabbage, brussels sprouts, kohlrabi, broccoli, and collard. Lanes 21-23 represent the AB genomes of $B$. juncea in the following order: rapid-cycling $B$. juncea, indian mustard, and $B$. juncea var. longidens. Lanes 24-26 represent the AC genomes of B. napus in the following order: rapid-cycling $B$. napus, colza, and rutabaga. Lanes 27-28 represent the BC genomes of $B$. carinata in the following order: rapid-cycling $B$. carinata and ethiopian mustard. Lane Cn represents the negative control of the PCR reaction (no template). Molecular marker sizes [M (100-bp ladder)] are shown at both flanking sides of the gel. Base pair length and specific genome amplification are given in the far left portion of the figure.

information revealed by RAPD markers (Thormann et al., 1994). Hence, the polymorphism is dependent on the ability of RAPD primers to recognize different priming sites in the genome. Priming sites can also be altered or exhibit differences between diploid and amphidiploid Brassica species as shown in Fig. 1 (primer bottom gel). For instance, accessions 10 and 11 are classified as belonging to the $\mathrm{B}$ genome and exhibit fragment length of 550 and $710 \mathrm{bp}$, respectively. Interestingly, accessions 21,22 , and 23, classified as $\mathrm{AB}$ genome, yielded only one of the two fragments (550 bp). On the contrary, accessions 27 and 28 classified as BC genome, have the $710 \mathrm{bp}$ fragment and not the $550 \mathrm{bp}$ fragment. It would be expected that the $\mathrm{AB}$ or $\mathrm{BC}$ species would share both the 550 and $710 \mathrm{bp}$ fragments observed for the $\mathrm{B}$ genome. The absence of one fragment could result from preferential amplification of PCR fragments in different genetic background ( $\mathrm{AB}$ and/or $\mathrm{BC}$ amphidiploids). Therefore, the presence of a homeologous genome affects the way PCR amplifies the specific B genome fragments. It is also possible that the target priming site has been lost due to a rearrangement such as a non-reciprocal translocation in the amphidiploid genomes (Lukens et al., 2005; Song et al., 1995; Udall et al., 2005). For example, in the AB genome, the 710-bp B fragment might have been lost by an exchanged with the A genome resulting in only two fragments, the one specific to the A genome and other to the B genome (550 bp). Further examination of the sequence of the amplified SCAR fragments might be necessary to access their physical nature.

Molecular DNA techniques will continue to facilitate germplasm characterization. The present research provides a set of 18 SCAR primers that can be used to discriminate among the six cultivated Brassica species (U-triangle). Moreover, these SCAR markers were able to identify two potentially misclassified $B$. rapa subspecies. The ideal descriptors are those that simply discriminate among the six cultivated Brassica species by amplifying genome-specific PCR products based on different length polymorphisms of a major single fragment. This is of extreme importance for sampling a large number of accessions to verify correct species assignments, especially at international and national germplasm banks. The amplification of a single fragment and reduced sensitivity to reaction conditions make these SCAR markers ideal for this task.

\section{Literature Cited}

Camargo, L.E.A., L. Savides, G. Jung, J. Nienhuis, and T.C. Osborn. 1997. Location of the selfincompatibility locus in an RFLP and RAPD map of Brassica oleracea. J. Hered. 88:57-60.

Dass, H. and H. Nybom. 1967. The relationships between Brassica nigra, B. campestris, $B$. oleracea, and their amphidiploid hybrids studied by means of numerical chemotaxonomy. Can. J. Genet. Cytol. 9:880-890.

Diers, B.W. and T.C. Osborn. 1994. Genetic diversity of oilseed Brassica napus germplasm based on nuclear restriction fragment length polymorphisms. Theor. Appl. Genet. 88:662-668.

dos Santos, B.J., J. Nienhuis, P. Skroch, J. Tivang, and M.K. Slocum. 1994. Comparison of RAPD and RFLPgenetic markers in determining genetic similarities among Brassica oleracea $\mathrm{L}$. genotypes. Theor. Appl. Genet. 87:909-915.

Gomez-Campo, C. 1980. Morphology and morphotaxonomy of the tribe Brassiceae, p. 3-31. In: S. Tsunoda, K. Hinata, and C. Gomez-Campo (eds.). Brassica crops and wild allies: Biology and breeding. Japan Scientific Societies Press, Tokyo.

Gomez-Campo, C. 1999. Biology of Brassica coenospecies. Elsevier, Amsterdam, The Netherlands.

Hasterok R. and J. Maluszynska. 2000. Cytogenetic analysis of diploid Brassica species. Acta Biol. Cracoviensis Ser. Botanica 42:145-153.

Heneen, W.K., B.Y. Chen, B.F. Cheng, A. Jonsson, V. Simonsen, R.B. Jorgensen, and J.Davik. 1995. Characterization of the A and C genomes of Brassica campestris and B. alboglabra. Hereditas 123:251-267.

Howell, E.C., G.C. Barker, G.H. Jones, M.J. Kearsey, G.J. King, E.P. Kop, C.D. Ryder, G.T. Teakle, J.G. Vicente, and S.J. Armstrong. 2002. Integration of the cytogenetic and genetic linkage maps of Brassica oleracea. Genetics 161:1225-1234.

Johns, M.A., P.W. Skroch, J. Nienhuis, P. Hinrichsen, G. Bascur, and C. Munoz-Schick. 1997. Gene pool classification of common bean landraces from Chile based on RAPD and morphological data. Crop Sci. 37:605-613.

Lazaro, A. and I. Aguinagalde. 1996. Phylogenetic relationships between the wild taxa of the Brassica oleracea L. group $(2 n=18)$ using the random amplified polymorphic DNA assay. Scientia Hort. 65:219-227.

Lukens, L.N., J.C. Pires, E. Leon, R. Vogelzang, L. Oslach, and T.C. Osborn. 2005. Patterns of sequence loss and cytosine methylation within a population of newly resynthesized Brassica napus allopolyploids. Plant Physiol. 140:336-348.

Negi, M.S., M. Devic, M. Delseny, and M. Lakshmikumaran. 2000. Identification of AFLP fragments linked to seed coat color in Brassica juncea and conversion to a SCAR marker for rapid selection. Theor. Appl. Genet. 101:146-152. 
Paran, I. and R.W. Michelmore. 1993. Development of reliable PCRbased markers linked to downy mildew resistance genes in lettuce. Theor. Appl. Genet. 85:985-993.

Perron, M.,A.G. Gordon, and J. Bousquet. 1995. Species-specific RAPD fingerprints for the closely related Picea mariana and P. rubens. Theor. Appl. Genet. 91:142-149.

Plieske J. and D. Struss. 2001. Microsatellite markers for genome analysis in Brassica. I. Development in Brassica napus and abundance in Brassicaceae species. Theor. Appl. Genet. 102:689-694.

Prakash S. and K. Hinata. 1980. Taxonomy, cytogenetics and origin of crop Brassicas, A review. Opera Botanica 55:1-57.

Quiros, C.F., J. Hul, P. This, A.M. Chevre, and M. Delseny. 1991. Development and chromosomal localization of genome-specific markers by polymerase chain reaction in Brassica. Theor. Appl. Genet. 82:627-632.

Quiros, C.F., P. This, M. Laudie, A. Benet, A-M. Chevre, and M. Delseny. 1995. Analysis of a set of RAPD markers by hybridization and sequencing in Brassica: A note of caution. Plant Cell Rpt. 14:630-634.

Rodriguez, J.M., T. Berke, L. Engle, and J. Nienhuis. 1999. Variation among and within Capsicum species revealed by RAPD makers. Theor. Appl. Genet. 99:147-156.

Skroch, P.W. and J. Nienhuis. 1995. Qualitative and quantitative characterization of RAPD variation among snap beans (Phaseolus vulgaris) genotypes. Theor. Appl. Genet. 91:1078-1085.

Snowdon, R.J., T. Friedrich, W. Friedt, and W. Köhler. 2002. Identifying the chromosomes of the A- and C-genome diploid Brassica species $B$. rapa (syn. campestris) and B. oleracea in their amphidiploid B. napus. Theor. Appl. Genet. 104:533-538.

Song, K.M., T.C. Osborn, and P.H. Williams. 1988a. Brassica taxonomy based on nuclear restriction fragment length polymorphisms (RFLPs). 1. Genome evolution of diploid and amphidiploid species. Theor. Appl. Genet. 75:784-794.
Song, K.M., T.C. Osborn, and P.H. Williams. 1988b. Brassica taxonomy based on nuclear restriction fragment length polymorphisms (RFLPs). 2. Preliminary analysis of subspecies within B. rapa (syn. campestris) and B. oleracea. Theor. Appl. Genet. 76:593-600.

Song, K.M., T.C. Osborn, and P.H. Williams. 1990. Brassica taxonomy based on nuclear restriction fragment length polymorphisms (RFLPs). 3. Genome relationships in Brassica and related genera and the origin of B. oleracea and B. rapa (syn. campestris). Theor. Appl. Genet. 79:497-506

Song, K., P. Lu, K. Tang, and T.C. Osborn. 1995. Rapid genome change in synthetic polyploids of Brassica and its implications for polyploid evolution. Proc. Natl. Acad. Sci. USA 92:7719-7723.

Suwabe K., H. Iketani, T. Nunome, T. Kage, and M. Hirai. 2002. Isolation and characterization of microsatellites in Brassica rapa L. Theor. Appl. Genet. 104:1092-1098.

Thormann, C.E., M.E. Ferreira, L.A.E. Camargo, J.G. Tivang, and T.C. Osborn. 1994. Comparison of RFLP and RAPD markers to estimating genetic relationships within and among cruciferous species. Theor. Appl. Genet. 88:973-980.

U, N. 1935. Genome analysis in Brassica with special reference to the experimental formation of B. napus and peculiar mode of fertilization. Jpn. J. Bot. 7:389-452.

Udall, J.A., P.A. Quijada, and T.C. Osborn. 2005. Detection of chromosomal rearrangements derived from homeologous recombination in four mapping populations of Brassica napus L. Genetics 169:967-979.

Villand,J.M. 1998. Molecular marker based characterization of Capsicum germplasm. PhD Diss., Univ. of Wisconsin, Madison.

Warwick, S.I and L.D. Black. 1992. Molecular relationships in subtribe Brassicinae (Cruciferae, tribe Brassiceae). Can. J. Bot. 71:906-918.

Wei, J.Z. and R.R.C. Wang. 1995. Genome and species-specific markers and genome relationships of diploid perennial species in Triticeae based on RAPD analysis. Genome 38:1230-1236. 